\title{
The green economy for sustainable development: a spatial multi-criteria analysis - ordered weighted averaging approach in the siting process for short rotation forestry in the Basilicata Region, Italy
}

\author{
Severino Romano, Mario Cozzi, Mauro Viccaro, Francesco di Napoli \\ Scuola di Scienze Agrarie, Forestali, Alimentari ed Ambientali, Università della Basilicata, \\ Potenza, Italy
}

\begin{abstract}
Optimising bioenergy chains and the creation of a bio-energy district can make a positive contribution to territorial development, land use planning and employment, while reducing environmental pollution. Energy planning issues are complex problems with multiple decision makers and criteria. Given the spatial nature of the problem, the present paper proposes a spatial multi-criteria analysis approach for supporting decision makers in the site selection process for short rotation forestry planting in the Basilicata Region, southern Italy. The methodology applied in the decision-support system is ordered weighted averaging, extended by means of fuzzy linguistic quantifiers. The purpose of the research is to formulate a systematic procedure to analyse complex decision problems, while supplying decision makers with a flexible tool to decide on possible agro-energy policies. The outcomes of the analysis may support decision makers in defining targeted agro-energy policies and help the private sector to identify the most appropriate cropping plan.
\end{abstract}

\section{Introduction}

Man's production and consumption of energy are among the factors responsible for global climate change. The major contributors to climate changes include the greenhouse gases (GHGs), of which $\mathrm{CO}_{2}$ is

Correspondence: Mario Cozzi, Scuola di Scienze Agrarie, Forestali, Alimentari ed Ambientali, Università della Basilicata, viale dell'Ateneo Lucano 10, 85100 Potenza, Italy.

Tel. +39.0971205424. E-mail: mario.cozzi@unibas.it

Key words: green economy, fuzzy analysis, multi-criteria spatial analysis, ordered weighted averaging, short rotation forestry.

Received for publication: 31 May 2013.

Revision received: 5 July 2013.

Accepted for publication: 8 July 2013.

(C) Copyright S. Romano et al., 2013

Licensee PAGEPress, Italy

Italian Journal of Agronomy 2013; 8:e21

doi:10.4081/ija.2013.e21

This article is distributed under the terms of the Creative Commons Attribution Noncommercial License (by-nc 3.0) which permits any noncommercial use, distribution, and reproduction in any medium, provided the original author(s) and source are credited. the primary element. There has been a big increase in its concentration levels, reaching $390 \mathrm{ppm}$ in 2010 , and rising by $39 \%$ as compared to pre-industrial levels (IPCC, 2011) (Data up-dated to January 2013 report that the concentration of $\mathrm{CO}_{2}$ has reached $395 \mathrm{ppm}$; available from: http:/www.esrl.noaa.gov/gmd/ccgg/trends/global.html). This has caused a trend for rising global mean temperatures. The World Bank report of November 2012 Turn Down the Heat: Why a $4^{\circ} \mathrm{C}$ Warmer World Must be Avoided (World Bank, 2012) highlights how the impact of a $4 \%$ increase in mean temperature (expected in 2060 given the current GHGs emission levels) may be catastrophic for mankind and for the ecosystems.

Several options have been identified to limit and reduce the climate change emissions in the atmosphere, including decarbonisation policies in production and consumption, and investment in the green economy. The United Nations Environment Programme (UNEP) defines a green economy as one that results in improved human well-being and social equity, while significantly reducing environmental risks and ecological scarcities (UNEP, 2011).

This approach to development suggests economic, legislative, technological and public education measures aimed at reducing the consumption of energy and natural resources, by promoting the increase in energy and production efficiency, the decrease in greenhouse emission gases, and the reduction in local and global pollution, through the promotion of a genuinely sustainable and lasting global economy. These measures mainly use renewable resources (such as biomasses, wind energy, solar energy, hydraulic energy) and focus on preventing as much waste as possible.

Bioenergy has a significant potential to mitigate GHG provided sustainable strategies are adopted to develop resources and efficient bioenergy systems are used (IPCC, 2011). Biomass is a primary source of food, fodder and fibres, and as a renewable energy source, in 2008, it provided approximately $10.2 \%$ (50.3 EJ) of global total primary energy supply (IPCC, 2011). Several studies confirm that there is still room for further development of the bio-energy sector (Berndes et al., 2003; Hoogwijk et al., 2005; de Vries et al., 2007; Hoogwijk et al., 2009), notably for short-rotation crops grown on farmland (Dornburg et al., 2008, 2010). Actually, following the IPCC report on renewable energies (IPCC, 2011) it would also be possible to obtain 700 EJ/year from dedicated biomass productions if used on abandoned lands and/or on soils not used for food crops.

In the Basilicata Region, southern Italy, marginal farmland areas are being increasingly abandoned because of their low productivity in terms of output and product type, and of the major reforms set out in the EU Common Agricultural Policy. There is no question that within this policy, the introduction of de-coupling, cross-compliance, rural development and nodulation has deeply changed the direct payment system to the farms, making a significant impact on the profile and maintenance of rural lands (Romano and Cozzi, 2008). The changes in agricultural activities in the Basilicata Region may be retraced by comparing the two most recent Agricultural General Censuses (ISTAT, 
$2000,2010)$ that show a significant reduction in the number of farms (36\%, down from 81,448 in 2000 to 51,756 in 2010) combined with a substantial reduction in the utilised agricultural area from 538 to 519 thousand hectares (ha) over the decade. The crops that have seen the biggest reduction include annual cereal crops that decreased by $31 \%$ (from 240,000 to $183,000 \mathrm{ha}$ ). A portion of that area has shifted to different crops, such as, e.g. trees and shrubs, while another portion has been abandoned and no longer represents agricultural areas. It follows that there is a large availability of soils suitable for bio-energy crops. This great potential has two main weaknesses linked with the selection of the species to cultivate and produce biomass (based on the specific site and climatic conditions of each area), and with the correct definition of the production and processing chains. The objective of the present work is to identify and apply a procedure based on a qualitativequantitative analysis aimed at identifying the species that are most suited to the features of the Basilicata Region, focusing on a robust methodology and with a detailed spatial component. The integration of multi-criteria analysis (MCA) and geographical information system (GIS) techniques may be useful to manage and solve conflicting situations in spatial contexts (Janssen and Rietved, 1990; Malczewski, 1996) and constitute an approach to land use suitability analysis (Carver 1991; Eastman, 1997; Thill, 1999; Malczewski, 2004). Such an integration may be thought of as a process that combines and transforms spatial and aspatial data (input) into a decision result (output), by defining a relationship between input and output maps with regard to geographical data and decision preferences, manipulated according to specified decision rules (Malczewski, 2004).

The most widely used multi-criteria analysis methods for land use evaluation in a GIS environment include Boolean overlay operations (non-compensatory combination rules) and the weighted linear combination methods (WLC, compensatory combination rules) (Heywood et al., 1995; Jankowski, 1995; Barredo, 1996; Beedasy and Whyatt, 1999; Malczewski, 2004; Romano and Cozzi, 2006).

There are, however, some major limitations associated with the use of such procedures in a decision process (Malczewski, 2004). Jiang and Eastman (2000) have dealt extensively with these limitations and suggest that the ordered weighted averaging (OWA) supplies an extension and a generalisation of the conventional map combination methods in GIS.

OWA is a family of multi-criteria combination procedures (Yager, 1988) that applies two series of weights: relatively important weights and ordered weights (or OWA). By specifying an appropriate set of OWAs, we can generate a wide range of different land use suitability maps.

Although this is a relatively new approach (Yager, 1988), we can find several reports in the literature of application of the conventional (quantitative) OWA in GIS environment (Asproth et al., 1999; Jiang and Eastman, 2000; Mendes and Motizuki, 2001; Rasmussen et al., 2001; Rinner and Malczewski, 2002; Makropoulos et al., 2003; Malczewski et al., 2003; Rashed and Weeks, 2003; Calijuri et al., 2004; Makropoulos and Butler, 2005). In this context, it is worthy of note that the GIS-OWA applications have so far focused on those procedures that require that the parameters associated with the operators be quantitatively specified. There is, however, some evidence to suggest that the traditional OWA operators have a poor applicability in situations that involve a high number of assessment criteria (Yager, 1996). In a complex spatial decision situation, decision makers might be expected to find it difficult (or even impossible, mainly for the problems that involve a number of criteria) to formulate accurate numerical information in relation to the OWA parameters (Malczewski, 2006). Actually, for a high number of assessment criteria, the main difficulty is to combine the criterion maps so that the results reflect decisions makers' preferences. In these circumstances, the key issues of decision making might be spec- ified in terms of some fuzzy linguistic quantifiers such as, for example, most criteria should be satisfied or at least $80 \%$ of criteria should be satisfied, etc. (Malczewski, 2006). This requires extending the conventional OWA so as to include situations that involve qualitative statements in the form of fuzzy linguistic quantifiers (Yager, 1988, 1996).

Contrary to the methodologies proposed in a GIS environment to assess the bio-energy resource potential in the forestry and agroforestry sector in Italy (Ragaglini et al., 2011; Tenerelli and Carver, 2012; Sacchelli et al., 2013a, 2013b), this work is aimed at developing a model for land use suitability analysis based on the use of natural language as the principle tool for human communication, so linguistic quantifiers prove to be very helpful in the computer-human interaction.

The above quantifiers translate specific mathematical expressions into a formal language that facilitates the expression of multi-criteria analysis procedures, notably the OWA. A linguistic quantifier can best represent the decision maker's qualitative information with regard to his or her perception of the relationship between different evaluation criteria, especially when the analysis involves a high number of criterion maps that makes it difficult, or even impossible, to make decisions and establish the most effective methodology.

The quantifier-guided OWA enables the decision maker to explore different decision strategies or scenarios, thus helping the operator to gain a better understanding of alternative land use suitability models.

\section{Materials and methods}

\section{Quantifier-guided ordered weighted averaging}

The multi-criteria analysis procedures in the GIS environment require different geographically defined alternatives (e.g. soil particles) and several assessment criteria represented by spatialised data. The problem is to combine the criterion maps following the criterion values (attributes) and the preferences of decision makers by using a decision rule (combination rule).

Assuming that an alternative is represented like a cell (raster) or a polygon, each alternative $(i=1,2, \ldots, m)$ is described by a set of standardised criterion values: $\mathrm{a}_{\mathrm{ij}} \in[0,1]$ for $i=1,2, \ldots, n$ (standardisation that may be done by means of fuzzy logical methods; Zadeh, 1965), and by preferences that are typically indicated as the criterion weights, $\mathrm{w}_{\mathrm{j}} \in[0,1]$ for $i=1,2, \ldots, n$, and $\Sigma_{j=1}^{n} w_{j}=1$ (calculated, e.g. through the analytical hierarchy process (AHP) (Saaty, 1980). Given some input data (a set of criterion maps and criterion weights), the OWA combination operator associates with an i-th location (e.g. raster or point) some ordered weights $v=v_{1}, v_{2}, \ldots, v_{\mathrm{n}}$ so that $v_{\mathrm{j}} \in[0,1]$ for $j=1,2, \ldots, n, \Sigma_{j=1}^{n} v_{j}=1$ and is defined as follows (Yager, 1988; Malczewski et al., 2003; Malczewski, 2006):

$$
O W A_{i}=\sum_{J=1}^{n}\left(\frac{u_{i} v_{i}}{\sum_{j=1}^{n} u_{i} v_{i}}\right) z_{i j}
$$

where: $z_{\mathrm{i} 1}>\mathrm{z}_{\mathrm{i} 2}>\ldots>\mathrm{z}_{\mathrm{in}}$ is the sequence obtained by rearranging the attribute values $\mathrm{a}_{\mathrm{i} 1}, \mathrm{a}_{\mathrm{i} 2}, \ldots, \mathrm{a}_{\mathrm{in}}$, and $\mathrm{u}_{\mathrm{j}}$ is the criterion weight based on the value of the attribute, $z_{i j}$. It is important to underline the difference between the two types of weight (criterion weights and order weights). Criterion weights are assigned to assessment criteria to indicate their relative importance. All the locations on the j-th criterion map are assigned the same weight of $\mathrm{w}_{\mathrm{j}}$. The order weights are associated with the criterion values pixel-by-pixel. They are assigned to the attribute value of the i-th position in a decreasing order without considering the criterion map the value is derived from. 
By different sets of order weights, a wide range of OWA operators may be generated, including the most common map combination procedures in GIS environment: the WLC and Boolean overlay operations, like the intersection (AND) and union (OR) (Yager, 1988; Malczewski et al., 2003; Malczewski, 2006).

The AND and OR operators represent the extreme cases of OWA and correspond, respectively, to the MIN and MAX operators. The order weights associated with the MIN operators are: $v_{\mathrm{n}}=1$, and $v_{\mathrm{j}}=0$ for all other weights. Given the order weights, $\mathrm{OWA}_{\mathrm{i}(\mathrm{MIN})}=\operatorname{MIN}_{\mathrm{j}}\left(\mathrm{a}_{\mathrm{i} 1}, \mathrm{a}_{\mathrm{i} 2}, \ldots, \mathrm{a}_{\mathrm{in}}\right)$, subsequent weights are associated with the MAX operator: $v_{1}=1$, and $v_{\mathrm{j}}=0$ for all other weights, and consequently $O W A_{i(M A X)}=M A X_{j}$ $\left(a_{\mathrm{i} 1}, a_{\mathrm{i} 2}, \ldots, a_{\mathrm{in}}\right)$. Assigning equal order weights (such as, $v j=1 / n$ for $j=1,2, \ldots, n)$, we obtain the conventional WLC, which is found at the central point in the continuum between the MIN and MAX operators (Yager, 1988), so that:

$$
O W A_{i(W L C)}=\sum_{j=1}^{n} w_{j} a_{i j}
$$

\section{Order weights: the use of fuzzy linguistic quantifiers}

As explained above, the OWA combination procedures involve two series of weights, namely criterion weights and order weights. The former may be calculated by different methods (Malczewski, 1999, 2006), including, for example, the AHP method, while for order weights it may be useful to use linguistic quantifiers as an expression of the human language in the computer-human interaction (Malczewski, 2006).

Given a set of criterion maps and a fuzzy linguistic quantifier $Q$, we can implement a procedure to combine criteria on the basis of a statement concerning the relationship between the evaluation criteria (Malczewski, 2006). For instance, the combination procedure may be guided by an instruction like: most criteria should be satisfied, or at least half the criteria should be satisfied, or all criteria should be satisfied, etc. This type of procedure is indicated as quantifier-guided multicriteria evaluation (Yager, 1996).

Based on the type of linguistic quantifier, we may distinguish absolute and relative (or proportional) linguistic quantifiers (Zadeh, 1983). Statements like at least about 4, about 5, nearly 10 , no more than 10 , over 5 , etc. provide examples of absolute quantifiers. Relative quantifiers indicate a proportional amount, such as most, many, a few, almost all, about half, about $60 \%$, etc. They may be represented as fuzzy sets in the unit range $[0,1]$ where 0 means $0 \%$ and 1 means $100 \%$. Therefore, if $\mathrm{Q}$ is a linguistic quantifier, it may then be represented as a fuzzy set $Q$ of the range $[0,1]$ where for each $p \in[0,1], Q(p)$ indicates the degree of compatibility of $p$ with the concept indicated by $Q$. For instance, if $Q$ is most and if $Q(0,95)=1$, it would mean that $95 \%$ is fully compatible with the idea transmitted by the linguistic quantifier most, whereas $Q(0,60)=0,75$ would indicate that $60 \%$ is only 0.75 compatible with the notion of most.

There are no empirical rules to demonstrate which one of the two classes of linguistic quantifiers is more suited to the multi-criteria evaluation. Malczewski proposes a set of proportional quantifiers known as regular increasing monotone (RIM) quantifiers (Yager, 1996; Malczewski, 2006). To identify the quantifier we use one of the simplest and more widely used methods to define a sub-set parametrised in the unit range (Yager, 1996), so that $Q(p)=p^{\alpha}, \alpha>0$, where $Q(p)$ is represented as a fuzzy set in the $[0,1]$ range. We can thus generate a whole family of RIM quantifiers. Table 1 shows a selection of RIM quantifiers and their features. By modifying the $\alpha$ parameter, we can generate different types of quantifiers and operators associated with the two extreme cases All and At least one. For $\alpha=1, Q(p)$ is proportional to so that it is indicated as Half quantifier (identity). For $\alpha$ tending to zero, the $\mathrm{Q}(\mathrm{p})$ quantifier approaches the extreme case of At least one, which corresponds to the MAX operator. For $\alpha$ tending to infinity, the $Q(p)$ quantifier approaches the extreme case of $A l l$, which corresponds to the MIN operator.

The notion of fuzzy quantifiers provides a method to generate order weights (Malczewski, 2006). Weights are based on the RIM quantifier. They are defined as follows (Yager, 1996):

$$
v_{j}=\left(\frac{\sum_{k=1}^{j} u_{k}}{\sum_{k=1}^{n} u_{k}}\right)^{\alpha}-\left(\frac{\sum_{k=1}^{j-1} u_{k}}{\sum_{k=1}^{n} u_{k}}\right)^{\alpha}
$$

It is important to note that in the multi-criteria evaluation procedures in a GIS environment, the criterion weights typically have the following property: $\sum_{j=1}^{n} w_{j}=1$. Hence, $\Sigma_{j=1}^{n} u_{j}=1$ and the previous equation may be simplified as:

$$
v_{j}=\left(\sum_{k=1}^{j} u_{k}\right)^{\alpha}-\left(\sum_{k=1}^{j-1} u_{k}\right)^{\alpha}
$$

so that the order weights $\mathrm{v}_{\mathrm{j}}$ derive from criterion weights, $\mathrm{w}_{\mathrm{j}}$. Given the criterion weights, $\mathrm{v}_{\mathrm{j}}$, and order weights, $\mathrm{v}_{\mathrm{j}}$, the quantified-guided OWA is defined as follows (Malczewski, 2006):

$$
\operatorname{OWA}_{\mathrm{i}}=\sum_{\mathrm{j}=1}^{\mathrm{n}}\left(\left(\sum_{\mathrm{k}=1}^{\mathrm{j}} \mathrm{u}_{\mathrm{k}}\right)^{\alpha}-\left(\sum_{\mathrm{k}=1}^{\mathrm{j}-1} \mathrm{u}_{\mathrm{k}}\right)^{\alpha}\right) \mathrm{z}_{\mathrm{ij}}
$$

The OWA calculated in a GIS environment supplies a tool to generate a wide range of decision-making strategies (alternative models of land use suitability) by specifying an appropriate linguistic quantifier (the parameter) and the set of weights associated to the OWA. The positions of OWA operators may be identified in the continuum that goes from the quantifier All to the quantifier At least one. There are two measures commonly used to identify the position of the OWA operator: the measures of tradeoff and ORness (Yager, 1988, 1996; Jiang and Eastman, 2000; Malczewski, 2006).

The tradeoff is a compensation measure (substitutability criterion). It indicates how much a poor performance on a criterion may be compensated by a good performance on other criteria being considered (Jiang and Eastman, 2000; Malczewski, 2006). Hence the measure of the tradeoff is within the $[0,1]$ range, so that 0 indicates the lack of compromise between criteria, whereas 1 indicates a full compromise (Table 1). The measure may be interpreted as the degree of scattering of OWA weights. In particular, the degree to which weights are uniformly distributed among all criteria controls the level of overall compromise between the criteria (Malczewski, 2006).

The position of the OWA in the continuum between the quantifier All and At least one may also be identified by specifying the degree of ORness (or degree of risk) (Yager, 1988, 1996; Malczewski, 2006). Also in this case, the degree of $\mathrm{OR}$ required goes from 0 (risk-averse, operator MIN, AND) to 1 (risk-taking, operator MAX, OR). As indicated in Table 1, the degree of ORness is also linked with the RIM quantifier. In particular, we can obtain different degrees of ORness by modifying the parameter $\alpha$ (Yager, 1988, 1996): the risk shifts from 0 to 1 for $\alpha$ that changes from infinity to zero (from All to At least one).

It is, therefore, evident that the space of the decision-making strategy is also defined by the two OWA measures, namely tradeoff and Orness (Figure 1).

\section{Case study area}

Bordering on the main regions in southern Italy (i.e. Campania, 
Puglia, Calabria), the region of Basilicata has a geographical area of 999,224 ha, with, according to 2011 national census statistics, a population of 578,036 inhabitants (ISTAT, 2011). It is mostly rural with twothirds of the population being concentrated in the few large urban centres. This explains the low regional population density (58.7 inhabitants per $\mathrm{km}^{2}$ ), well below the national average (approx. 201 inhabitants per $\mathrm{km}^{2}$ ).

The territory of Basilicata (also called Lucania) shows wide morphological differences, ranging from the limestone base of the Murge hills and the Bradano depression in the north-east to the mountainous and hilly areas of the Apennine range, characterised by ridges running in a NW-SE direction, and to the Ionian coastal plains (AA.VV., 2006).

Climatic conditions are specifically related to the complex orography of the region. This is marked by very sharp differences in elevation ranging from sea level to over $2200 \mathrm{~m}$, and by its geographical position, surrounded as it is by three seas: the Adriatic to the north-east, the Tyrrhenian to the south-west, and the Ionian to the south-east. As pointed out by Cantore et al. (1987), a large portion of the territory shows typically Mediterranean features (Ionian coast, Bradano depression and Murge hills around Matera), with areas above $800 \mathrm{~m}$ asl characterised by a temperate-cool climate with quite dry summers.

Average annual rainfall ranges from 529 to approximately $2000 \mathrm{~mm}$ and is concentrated in the south-west area of the region, since the Apennine range intercepts most of the Atlantic weather perturbations that enter the Mediterranean. The months with the highest rainfall are November and December, while the driest are July and August, when severe drought spells are frequent.

There are large seasonal variations in temperature with very hot summers and very cold winters. The coldest month is usually January with an average temperature between 4 and $7^{\circ} \mathrm{C}$.

The total agricultural area is estimated to be 489,229 ha (48.96\% of the regional surface area) and the area used for agriculture is equal to 368,726 ha, of which $57.72 \%$ is used to grow arable crops (mostly under rain-fed conditions) and $10.77 \%$ for orchards, mostly located in hilly areas. The remaining surface (31.28\%) is under permanent grassland and meadows mainly located in mountain areas, with 2009 ha cropped with deciduous trees and only 30.74 ha with energy crops (ISTAT, 2010). Forest areas present an extremely natural environment with mosaic landscapes made up of many endemic species and intercropping. Forested areas cover 354,895 ha, with a forest area index equal to $35.6 \%$ (INEA, 2006). In terms of species distribution, the most representative physiognomic categories include mesophilic and meso-thermophilic oak woods that account for $51.8 \%$ of the total forest area. This is followed by beech woods (8.4\%), the Mediterranean maquis (7.9\%), thermophilic shrubs (6.9\%), and other broad-leaved forests (5.5\%).

\section{Study area profiling}

Profiling of the case study area was carried out entirely in a GIS environment. Georeferenced raster layers ( $100 \mathrm{~m}$ resolution) were created for each single environmental factor under investigation using Gauss Boaga East, on Monte Mario Roma 1940 datum as geographical reference system.

Table 1. Features of regular increasing monotone to select the value of $\alpha$.

\begin{tabular}{|c|c|c|c|c|}
\hline Quantifier (Q) & $\alpha$ & GIS combination procedures & ORness & Tradeoff \\
\hline At least one & $\alpha \rightarrow 0$ & OWA (OR, MAX) & 1.0 & 0.0 \\
\hline At least a few & $\alpha=0.1$ & OWA & $*$ & * \\
\hline A few & $\alpha=0.5$ & OWA & $*$ & * \\
\hline Half (identity) & $\alpha=1$ & OWA (WLC) & 0.5 & 1.0 \\
\hline Most & $\alpha=2$ & OWA & $*$ & $*$ \\
\hline Almost all & $\alpha=10$ & OWA & * & $*$ \\
\hline All & $\alpha \rightarrow \infty$ & OWA (AND, MIN) & 0.0 & $0.0^{*}$ \\
\hline
\end{tabular}

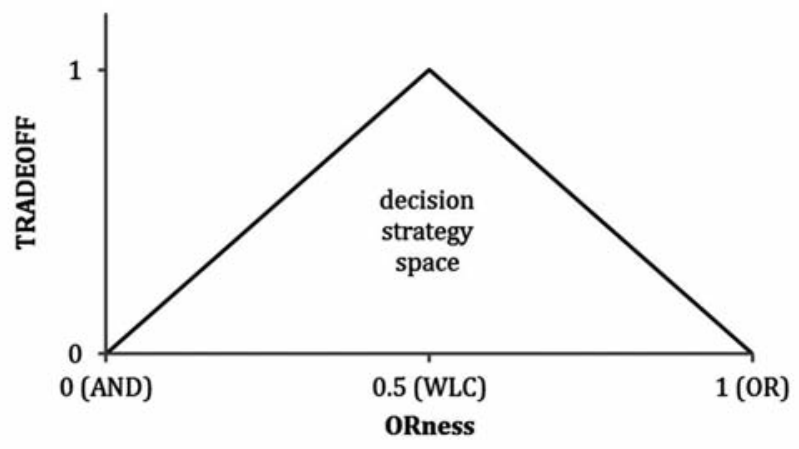

Figure 1. Space of decision-making strategy: relationship between tradeoff and ORness measures.
Table 2. Environmental factors under analysis.

\begin{tabular}{lc} 
Factor & Unit \\
Average annual precipitation & $\mathrm{mm}$ \\
Average precipitation in summer months & $\mathrm{mm}$ \\
\hline Mean annual temperature & ${ }^{\circ} \mathrm{C}$ \\
Mean temperature in the coldest month & ${ }^{\circ} \mathrm{C}$ \\
\hline Elevation & $\mathrm{m}$ asl \\
Slope & $\%$ \\
\hline Soil depth* & $\mathrm{cm}$ \\
Carbonates* & $\%$ of CaCO \\
\hline Soil reaction* & $\mathrm{pH}$ \\
Soil texture* & Textural classes
\end{tabular}

*Values grouped in classes (Table 3). $\mathrm{CaCO}_{3}$, calcium carbonate. 
The environmental factors (criteria) used in the geographical information system (Table 2) are closely related to the ecological and cropping needs of the species under investigation, with special reference to the elevation profile, the water, temperature, edaphic and cropping requirements (crop mechanisation) (Table 3 ).

In the present paper, and for the purpose of analysis, among the many species suitable for energy crops (El Bassam, 2010) we identified the woody species that, on the basis of several research experiences, have been shown to be more suitable for short rotation forestry (SRF) in Italy (Mercurio and Minotta, 2000; Bergante and Facciotto, 2006; Facciotto et al., 2006; Minotta et al., 2007), such as Eucalyptus camaldulensis Dehn, Populus x euroamericana Guinier, Robinia pseudoacacia L. Salix alba L. The analysis also involved the production of the regional forest map and land use map (constraints) for the purpose of identifying only the areas potentially destined for SRF intervention. Those soils whose potential use was not suitable for SRF were excluded. These included artificial areas, permanent crops (orchards, vineyards, olive groves), woodlands, wetlands and water bodies.

\section{Analysis of land use suitability}

The analysis of land use suitability for SRF planting was made using a geographical analysis model, where environmental evaluations are made through the joint use of MCA techniques and GIS. In a complex decision-making context, the previously described method allows for different alternatives to be considered, achieving a result that complies with the decision preferences that have been specified through a welldefined sequence of processes (Figure 2).

Once the criteria required for the specific analysis are identified, they are subsequently standardised using fuzzy spatial functions (Figure 3). These are chosen on the basis of the type of data treated and the uncertainty associated with it. Therefore, new raster images were obtained with the suitability values $[0,1]$ of the species to the area, based on each single environmental factor considered.

Once criteria have been standardised, the previously described method requires the calculation of two series of weights: criterion weights and order weights. The former have been calculated by the AHP method by making a pair comparison using the Saaty matrix (Saaty, 1980). The identification of fuzzy functions and the allocation of criterion weights for each factor under analysis have been based on the evaluation made by a team of experts in agronomy, arboriculture, soil chemistry and soil science. The order weights, whose calculation part- ly depends on criterion weights, have been determined by making use of RIM linguistic quantifiers using the method proposed by Malczewski (2006). The procedure requires arranging criteria based on their value (criterion value) in decreasing order for arranging criterion weights. Since criteria are represented by raster images constituted by the same number of pixels but of different values, it may be assumed that the representative value for each single raster image is represented by the average value of all pixels. Once the average is calculated for each criterion, values are arranged and criterion weights are determined accordingly. The next step concerns the calculation of order weights (Eq. 4) on the basis of criterion weights and of the value representative for each linguistic quantifier Q (Table 1), thus obtaining a set of order weights (e.g. Annex 1).

By implementing the model and incorporating the constraints under consideration, seven suitability maps were obtained for each single species relating different OWA operators, including AND, OR operators and the conventional WLC.

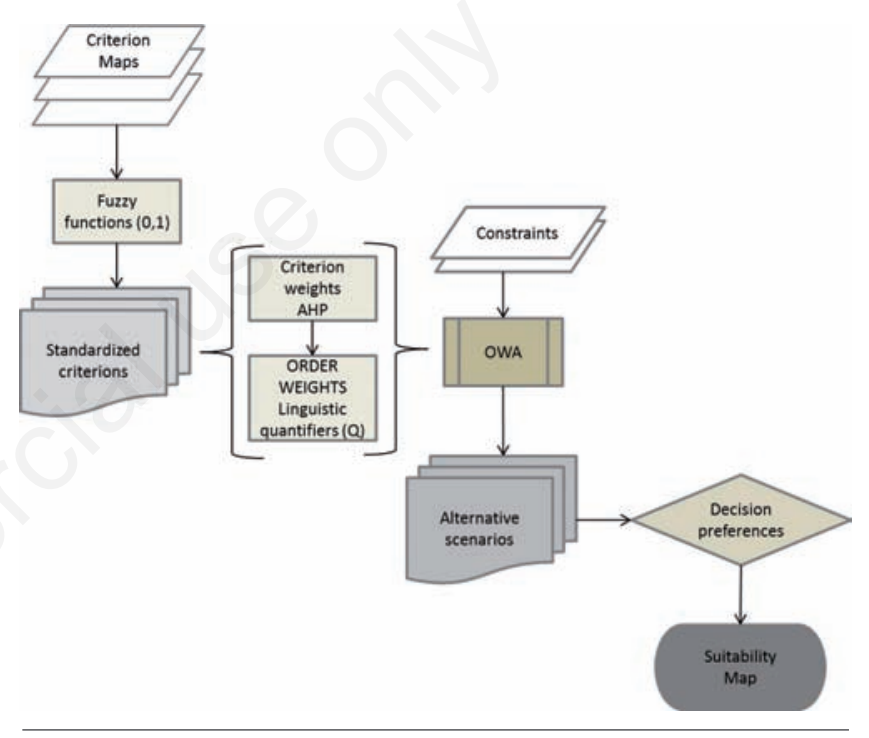

Figure 2. Layout of the analytical model. OWA, ordered weighted averaging.

Table 3. Representative value for each class.

\begin{tabular}{|c|c|c|c|c|c|}
\hline \multirow[b]{2}{*}{ Class } & \multicolumn{2}{|c|}{ Carbonates } & \multicolumn{3}{|c|}{ Reaction } \\
\hline & $\mathrm{CaCO}_{3}(\%)$ & Value & Class & $\mathrm{pH}$ & Value \\
\hline Non calcareous & $<0.5$ & 1 & Very acid & $<4.5$ & 1 \\
\hline Very weakly calcareous & $0.5-1.0$ & 2 & Acid & $4.5-5.5$ & 2 \\
\hline Weakly calcareous & $1.0-5$ & 3 & Sub-acid & $5.6-6.5$ & 3 \\
\hline Moderately calcareous & $5-10$ & 4 & Neutral & $6.6-7.3$ & 4 \\
\hline Very calcareous & $10-25$ & 5 & Sub-alkaline & $7.4-7.8$ & 5 \\
\hline Strongly calcareous & $25-40$ & 6 & Alkaline & $7.9-8.4$ & 6 \\
\hline \multirow[t]{2}{*}{ Extremely calcareous } & $>40$ & 7 & Very alkaline & $8.5-9.0$ & 7 \\
\hline & \multicolumn{2}{|c|}{ Depth } & \multicolumn{3}{|c|}{ Texture } \\
\hline Class & Depth $(\mathrm{cm})$ & Value & Class & Soil type & Value \\
\hline Very fine & $<25$ & 1 & Coarse & S, LS & 1 \\
\hline Fine & $25-50$ & 2 & Moderately coarse & SL & 2 \\
\hline Moderately deep & $50-100$ & 3 & Medium & L, ZL, Z & 3 \\
\hline Deep & $100-150$ & 4 & Moderately fine & SCL, CL, ZCL & 4 \\
\hline Very deep & $>150$ & 5 & Fine & C, SC, ZC & 5 \\
\hline
\end{tabular}

$\mathrm{CaCO}_{3}$, calcium carbonate; $\mathrm{S}$, sand; L, loam; Z, silt; C, clay. 
Figure 4 shows an example of the seven alternative maps of land use suitability for the development of the woody species under analysis. Each map is associated with a linguistic quantifier, a parameter , and with different measures of tradeoff and ORness. The figure associated with the fuzzy linguistic quantifier All (MIN operator) represents the worst suitability scenario in which the lowest values are assigned to each pixel. By reducing the value of parameter $\alpha$ from $\alpha \rightarrow \infty$ to $\alpha=1$ the ORness degree increases from 0 to 0.5 and tradeoff from 0 to 1 . This involves an increase in suitability values for each pixel (increasingly optimistic scenario). The suitability map associated with the linguistic quantifier Half $(\alpha=1)$ represents the strategy corresponding to the conventional WLC. Such a strategy is characterised by an ORness of 0.5 and a full tradeoff. By reducing the value of $\alpha$ from 1 to 0 there is an increase in the degree of ORness and a reduction in the degree of tradeoff; the figure associated with the fuzzy linguistic quantifier $A t$ least one (MAX operator) represents the most optimistic scenario of land use suitability for energy crops. This scenario corresponds to the
OR operator with ORness equal to 1 and tradeoff to 0 .

Hence considering the linguistic quantifiers and different ORness and tradeoff degrees the decision maker can identify the best solution according to the specified decision needs.

\section{Results}

Given the lack of experimental fields of energy crops in the region, it is difficult to test the model and select which one among the maps obtained is most suited to represent the real-life scenario, as carried out for the land use suitability analysis for SRF at a national level (Salvati et al., 2007). So the choice of the most representative map of each single species is based on consideration of the ecological and cropping needs, the ORness degree, and the distribution of corresponding suitability values.

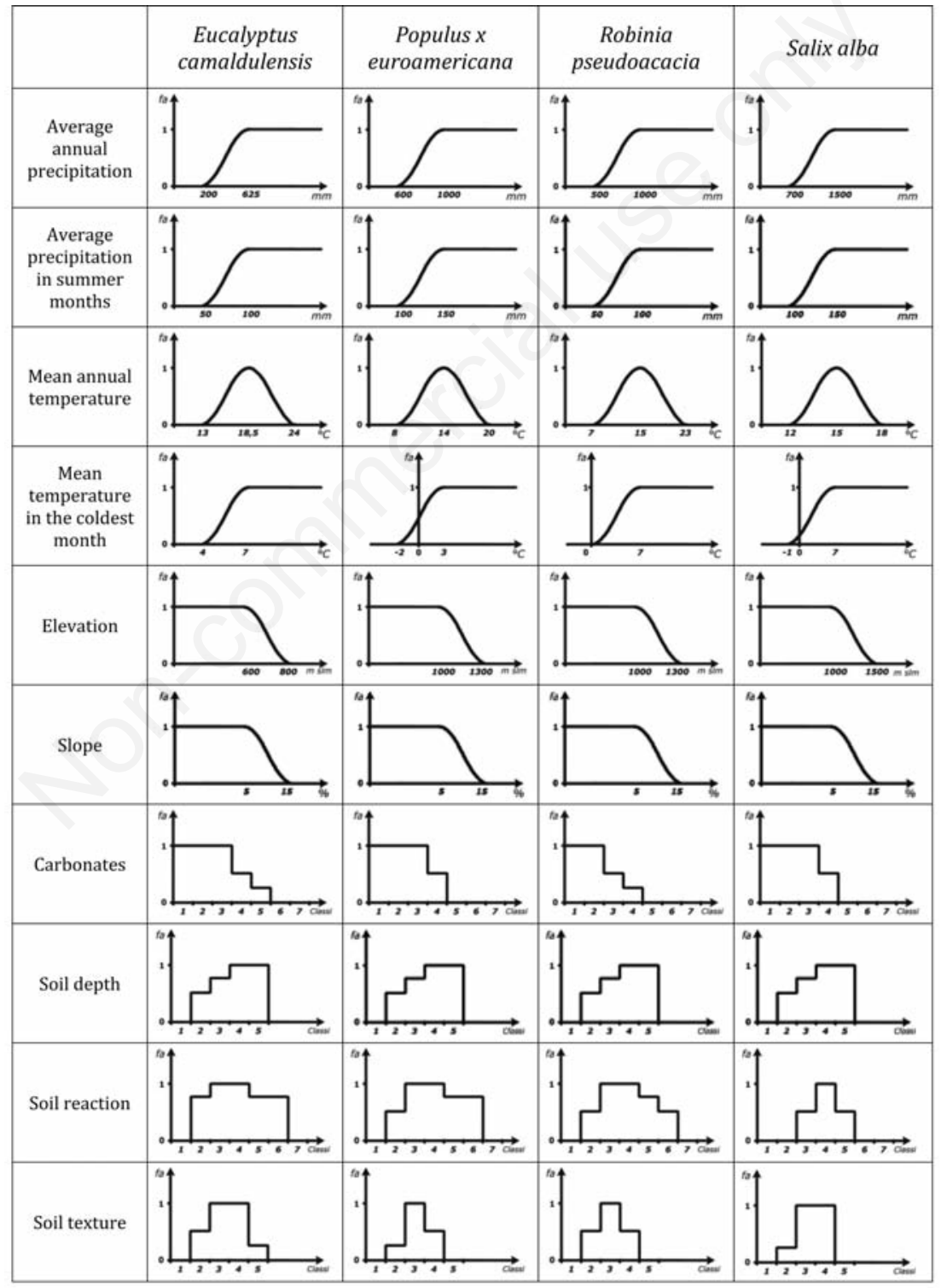

Figure 3. Fuzzy membership functions representative of land suitability for cultivation of target species as influenced by the environmental factors under analysis. 
The success of SRF planting depends on the fact that the species can find the best climatic and edaphic conditions (soil type and summer drought, in particular) and that plantation management is optimal, also taking into account cropping requirements (i.e. mechanisation and lack of irrigation). It is evident that the higher the number of criteria considered in the analysis the more reliable the result. The linguistic quantifiers that best express this concept and that have contributed to the calculation of order weights are: all criteria should be satisfied (All quantifier), almost all (Almost all) and most (Most). Moreover, these quantifiers are associated with a low ORness degree (low risk). Considering that shifting from 0 to 10 Rness values ranges from higher risk-aversion to higher risk propensity, and given the absence of field experimental data to test the model, the choice of the three quantifiers is obviously justified for the low associated risk.

Lastly, in order to choose the most appropriate among the three maps relating different quantifiers, an analysis was carried out to assess the distribution of map suitability values. As we can clearly see in different box plots (Figure 5) the final choice of the map associated with the

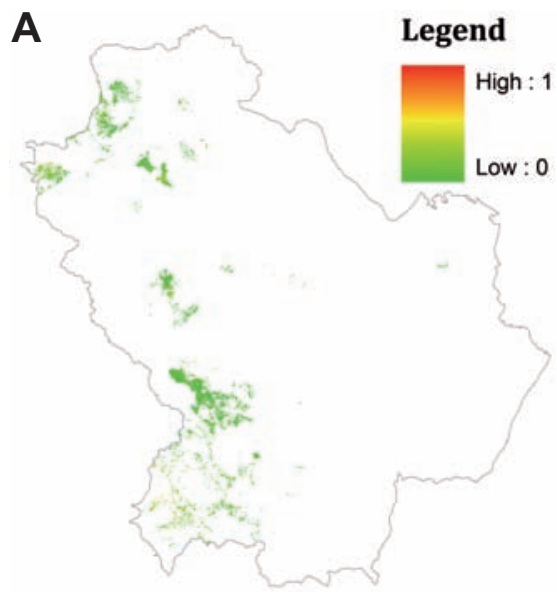

B
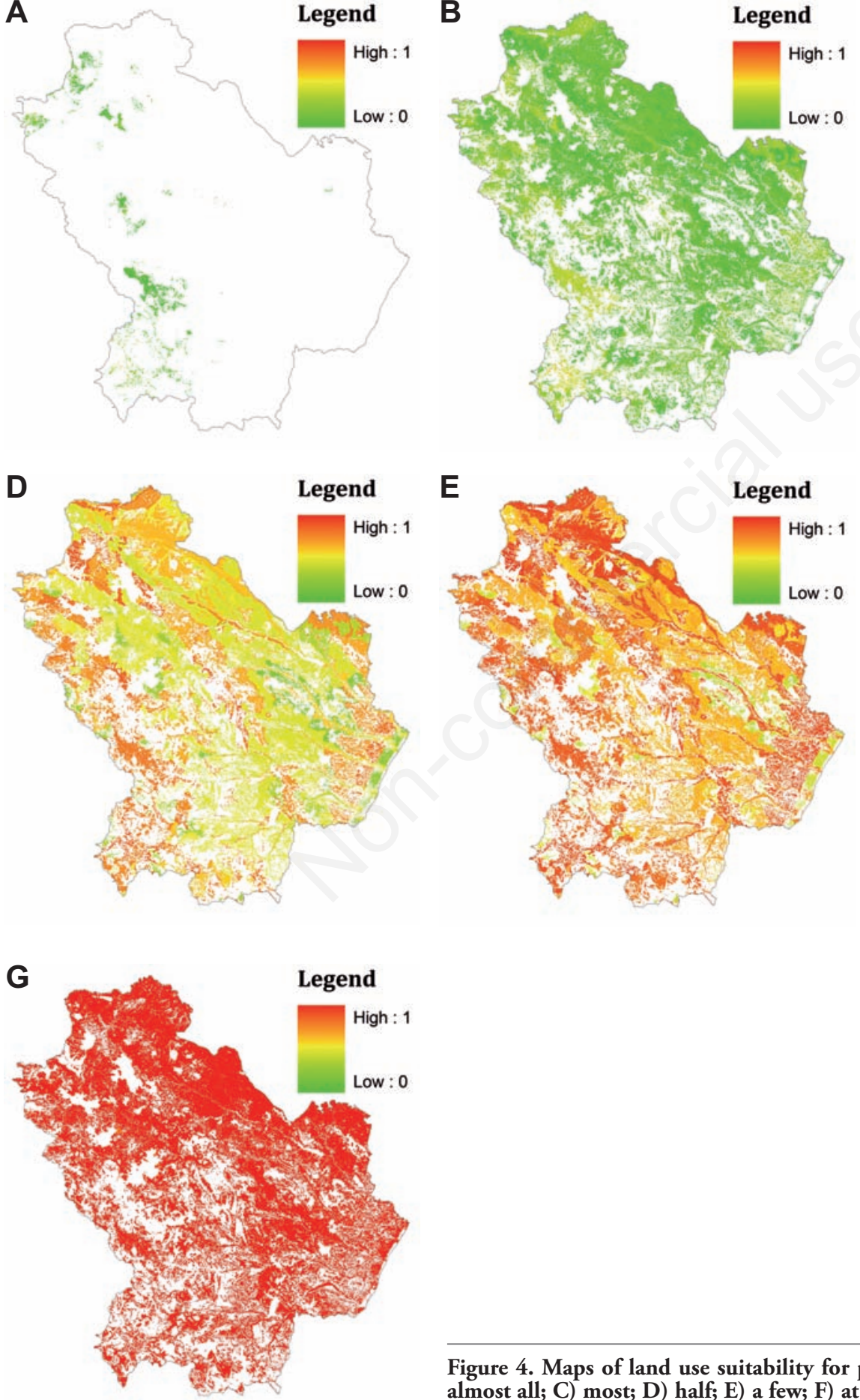

E
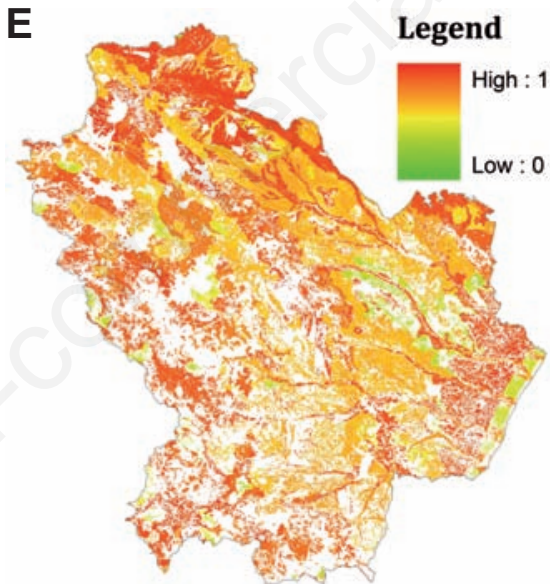

$\mathbf{F}$

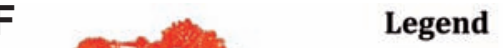

Legend
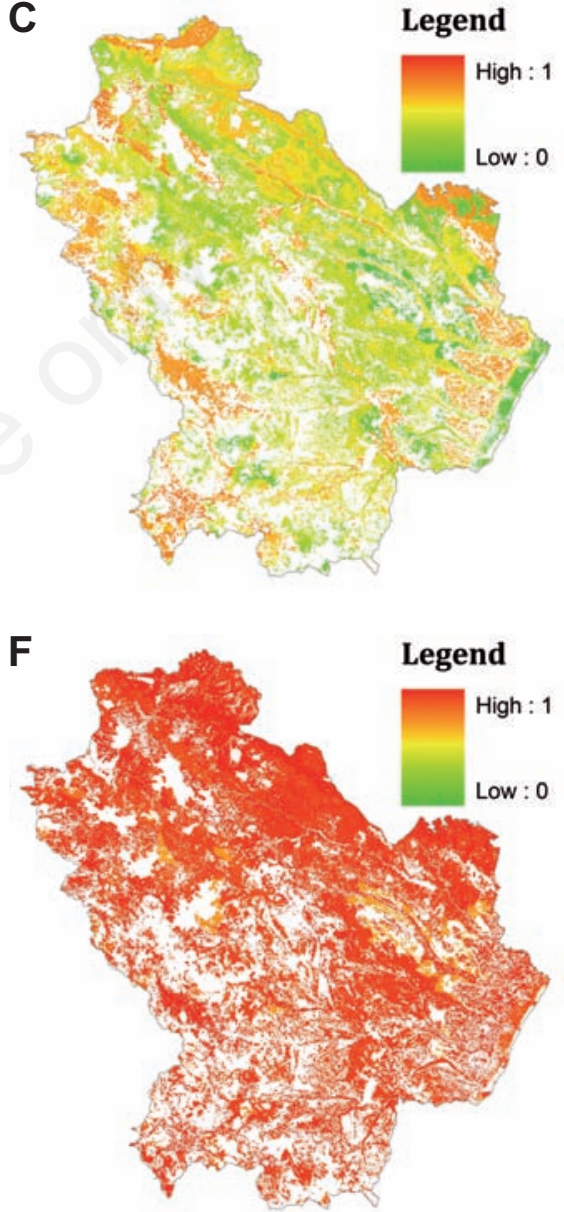

Figure 4. Maps of land use suitability for planting Populus $x$ euroamericana: A) all; B) almost all; C) most; D) half; E) a few; F) at least a few; G) at least one. 
A

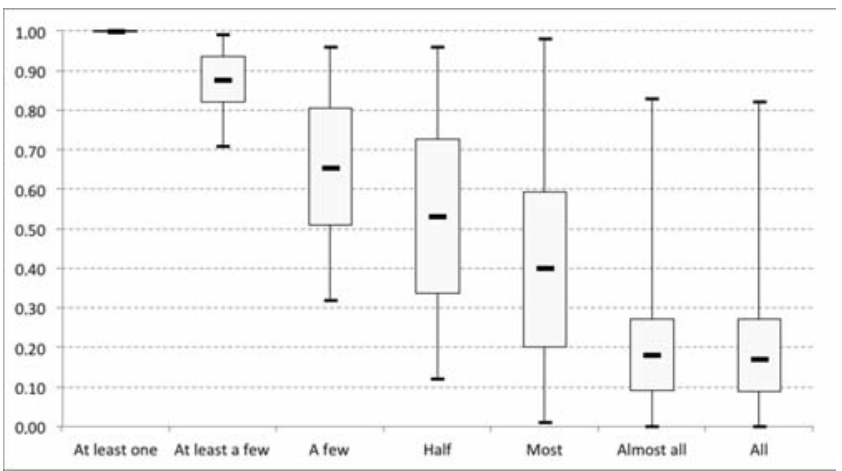

C

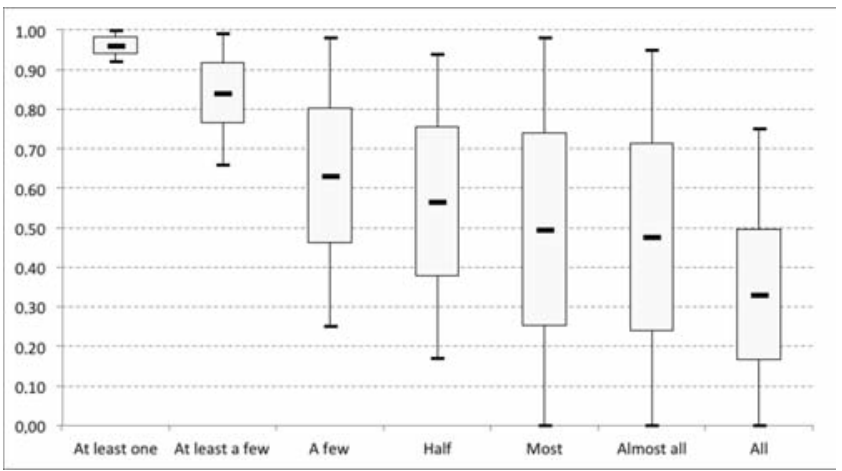

B

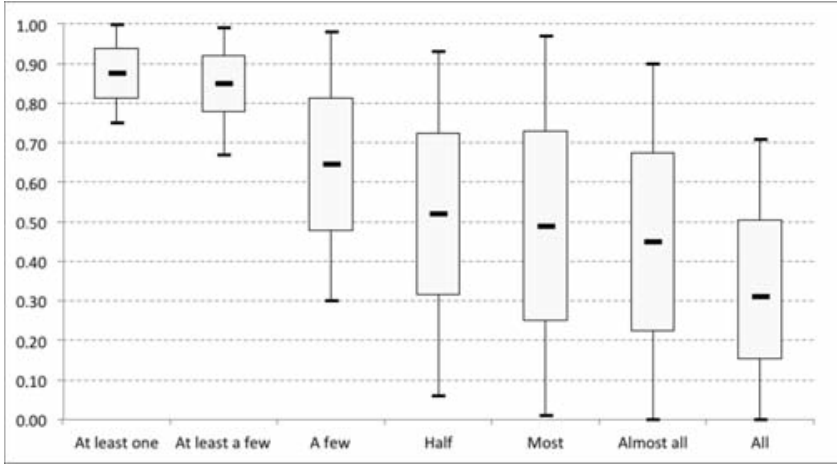

D

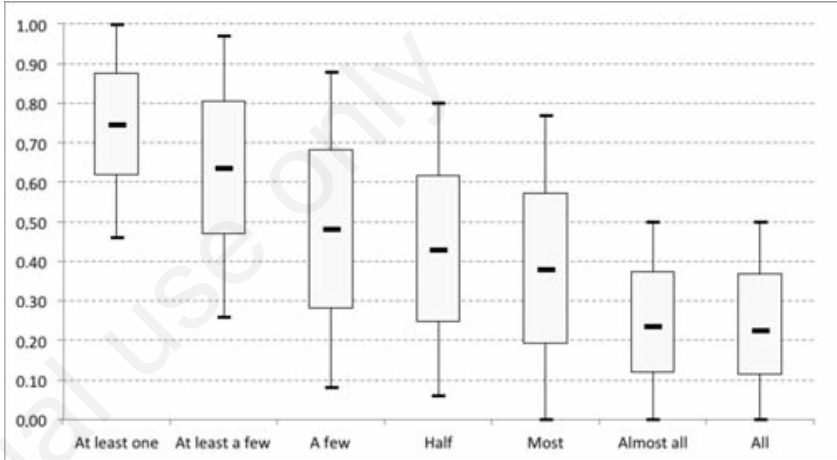

Figure 5. Box-plot: distribution of suitability values in different scenarios for the four species considered. A) E. camaldulensis; B) P. $x$ euroamericana; C) R. pseudoacacia; D) S. alba.

Most quantifier is justified by the fact that it shows a wide range of suitability values with quite a uniform distribution. For a clear interpretation of results, obtained through the OWA model, the values have been discretised using other types of linguistic quantifier (Chen et al., 1992). They constitute a sound and well-consolidated tool for the conversion of cardinal values into quality attributes. By using them, it is indeed possible to give a mathematical representation of a linguistic term. Thus, it has been possible to consider as unsuitable the territories with values in the $0-0.77$ range and as suitable the values in the 0.77-1 range.

Through a re-classification of maps it has been possible to identify only the suitable soils with a surface area equal to 4659 ha, 8847 ha and 8225 ha, respectively, for eucalyptus, poplar and black locust, against the 641,808 ha available for SRF in the region; instead, the willow showed no suitability.

Maps were later overlapped so as to identify, from among the three species that resulted suitable, the most appropriate to SRF in the region. Moreover, in the areas that could be fit for different species, priority was given to eucalyptus for its higher winter-hardiness in Mediterranean environments and its greater resistance to diseases as compared to poplar; this was followed by poplar and black locust.

Results show that the areas occupied by poplar and eucalyptus remain unchanged, namely 8847 ha and 4659 ha, respectively, whereas a loss was observed for the black locust to which a low priority was associated in the areas fit for several species, with an occupied surface area of 4742 ha.

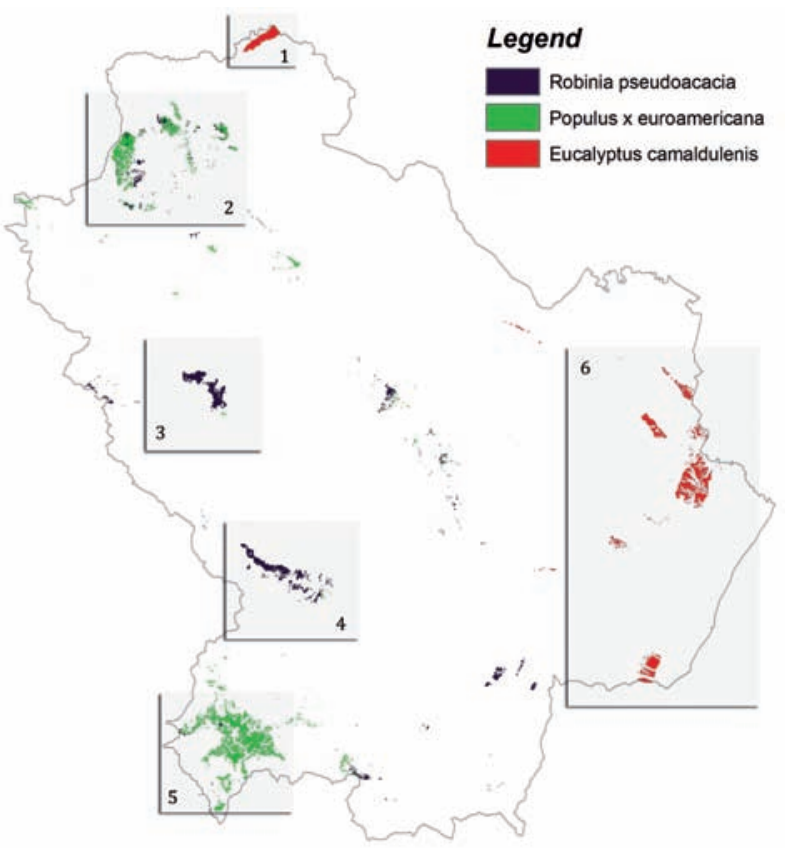

Figure 6. Suitability level of the area of the Province of Potenza for short rotation forestry. 
The results of the model developed (Figure 6) have indicated that, following the peculiarities of the territory characterised by great climatic differences due to the orographic complexity, eucalyptus has resulted suitable for the areas classified as having a Mediterranean climate, especially for summer drought levels, such as the Metaponto (6) and Melfi (1) plains. On the contrary, poplar and black locust resulted suitable for the areas with continental characteristics on the Apennine ridge, where most annual precipitation is concentrated and the average annual temperatures do not allow the development of species like eucalyptus, especially on the plains underlying the Vulture mountain (2), in the wide valleys of the Agri (3) and the Lagonegro (4), and on the Tyrrhenian side of the region (5).

This evidence goes some way to confirm the effectiveness of the applied method in large-scale land planning models.

\section{Conclusions}

This article proposes a model of land use suitability analysis by means of linguistic quantifiers in GIS. The natural language is the major tool for human communication so that these fuzzy (or linguistic) quantifiers constitute a chief means of computer-human interaction. It has indeed been possible to translate specific mathematical expressions into a formal language that has then resulted in the formulation of OWA procedures. The work has shown how a wide range of multi-criteria strategies can be obtained by the application of appropriate linguistic quantifiers, including the conventional overlay and WLC Boolean operators. A linguistic quantifier can best represent the quality information of the decision maker in relation to his or her perception of the relationship of different evaluation criteria, in particular when a high number of criterion maps are involved in the analysis.

In these circumstances it is difficult, if not impossible, to make choices and establish the most effective methodology. The quantifierguided OWA allows the decision maker to explore different decision strategies or scenarios, promoting a better understanding of the alternative models of land use suitability. In fact, this case study has confirmed that choosing the most suitable areas for planting specialised energy crops requires analysis of a large number of different criteria. However, we were able to obtain seven alternative suitability scenarios to choose from, according to the specific needs of the decision maker. Indeed, after comparing the maps, the quantifier Most was chosen because it seemed to best represent the kind of analysis carried out in relation to the high number of criteria associated with the environmental factors required to ensure the growth of a tree species. Moreover, as the model could not be tested due to the lack of experimental fields, the choice has also been justified for its low level of ORness association.

Different scenarios are also available, so that, assuming the needs of the decision maker may change, the choice can be directed towards other scenarios. For example, if irrigation is to be applied, you may assume you take a higher risk connected with the analysis and you consider less criteria which, however, are not excluded from the analysis itself. Therefore, the choice can concern the scenarios Half (corresponding to the conventional WLC) or $A$ few, both characterised by a higher ORness, the former also being distinguished by a full tradeoff.

Furthermore, based on the knowledge of the area concerned and of the subject under study, as well as the associated risk, it is possible to identify beforehand the linguistic quantifier that will result in the OWA procedures, without implementing necessarily different scenarios.

In our case study, having identified eucalyptus, poplar, black locust and willow species for SRF due to their ecological features which make them suitable for the area under analysis, and considering that their growth is actually ensured by a high number of ecological factors, we could have chosen directly the quantifier Most that fully expresses this concept and carried out the land use suitability analysis, partly considering the low risk associated with it, in the absence of experimental fields that could provide indications on the suitability of those species.

The proposed methodology is shown to be very flexible compared to other MCA methods, in particular for the possibility to make the choice in qualitative rather than quantitative terms, which are often difficult to characterise. Although it is true that in the quantitative OWA the calculation of order weights is made in relation to the ORness degree, it is not always easy to choose the value of the latter, notably in land use analysis models, whereas it is much easier to express choices in linguistic terms as regards the number of criteria to consider, taking into account that each quantifier is associated with different ORness and tradeoff levels.

\section{References}

AA.VV., 2006. I suoli della Basilicata. Regione Basilicata; Dipartimento Agricoltura, Sviluppo Rurale, Economia Montana; Ufficio risorse naturali in agricoltura, Italy.

Asproth V, Holmberg SC, Håkansson A, 1999. Decision Support for spatial planning and management of human settlements. In: G.E. Lasker (ed.), Advances in support systems research, vol. 5. Int. Inst. Adv. Stud. Syst. Res. Cybernetics, Windsor, Ont., Canada, pp. 30-9.

Barredo JI, 1996. Sistemas de informacion geografica y evaluacion multicriterio en la ordenacion del territorio. Ra-Ma, Madrid, Spain.

Beedasy J, Whyatt D, 1999. Diverting the tourists: aspatial decisionsupport system for tourism planning on a developing island. J. Appl. Earth Observ. Geoinform. 3/4:163-74.

Bergante S, Facciotto G, 2006. Impianti annuali, biennali, quinquennali: produttività e costi in alcune realtà del Nord Italia. Sherwood 128:25-30.

Berndes G, Hoogwijk M, van den Broek R, 2003. The contribution of biomass in the future global energy system: a review of 17 studies. Biomass Bioener. 25:1-28.

Calijuri ML, Marques ET, Lorentz JF, Azevedo RF, Carvalho CAB, 2004. Multi-criteria analysis for the identification of waste disposal areas. Geotech. Geol. Eng. 22:299-312.

Cantore V, Iovino F, Pontecorvo G, 1987. Aspetti climatici e zone fitoclimatiche della Basilicata. Istituti di Ecologia e Idrologia Forestale. C.N.R. IEIF, Cosenza, Italy.

Carver SJ, 1991. Integrating multi-criteria evaluation with geographical information systems. Int. J. Geogr. Inform. Syst. 5:321-39.

Chen SJ, Hwang CL, 1992. Fuzzy multiple attribute decision making: methods and applications. Springer-Vergal, Berlin, Germany.

de Vries B, Hoogwijk MM, van Vuuren D, 2007. Renewable energy sources: their global potential for the first half of the 21st century at a global level: an integrated approach. Energy Policy 35:2590610 .

Dornburg V, Faaij A, Verweij P, Langeveld H, van de Ven G, Wester F, van Keulen H, van Diepen K, Meeusen M, Banse M, Ros J, van Vuuren D, van den Born GJ, van Oorschot M, Smout F, van Vliet J, Aiking H, Londo M, Mozaffarian H, Smekens K, Lysen E, van Egmond S, 2008. Assessment of global biomass potentials and their links to food, water, biodiversity, energy demand and economy. WAB 500102012 , The Netherlands Environmental Assessment Agency, Bilthoven, The Netherlands.

Dornburg V, van Vuuren D, van de Ven G, Langeveld H, Meeusen M, Banse M, van Oorschot M, Ros J, van den Born GJ, Aiking H, Londo M, Mozaffarian H, Verweij P, Lysen E, Faaij A, 2010. Bioenergy revisited: key factors in global potentials of bioenergy. Energy 
Environ. Sci. 3:258-67.

El Bassam N, 2010. Handbook of bioenergy crops: a complete reference to species, development and applications. ed. Earthscan LLC, Washington, DC, USA.

Eastman JR, 1997. Idrisi for Windows, version 2.0: tutorial exercises. Graduate School of Geography-Clark University, Worcester, MA, USA.

Facciotto G, Bergante S, Lioia C, Rosso L, Mughini G, Zenone T, Nervo G, 2006. Produttività di cloni di pioppo e salice in piantagioni a turno breve. Forest@3:238-52.

Heywood I, Oliver J, Tomlinson S, 1995. Building an exploratory multicriteria modelling environment for spatial decision support. In: P. Fisher (ed.) Innovations in GIS, vol. 2. Taylor \& Francis, London, UK, pp 127-36.

Hoogwijk M, Faaij A, de Vries B, Turkenburg W, 2009. Exploration of regional and global cost-supply curves of biomass energy from short-rotation crops at abandoned cropland and rest land under four IPCC SRES land-use scenarios. Biomass Bioener. 33:26-43.

Hoogwijk M, Faaij A, Eickhout B, de Vries B, Turkenburg W, 2005. Potential of biomass energy out to 2100 , for four IPCC SRES landuse scenarios. Biomass Bioener. 29:225-57.

INEA, 2006. Carta forestale della Basilicata: Atlante. INEA, Potenza, Italy.

IPCC (International Panel of Climate Change), 2011. Special report on renewable energy sources and climate change mitigation. Cambridge University Press, United Kingdom and New York, NY, USA.

ISTAT, 2000. $5^{\circ}$ Censimento generale dell'agricoltura 2000. Available from: http:/www.istat.it/it/censimento-agricoltura

ISTAT, 2010. $6^{\circ}$ Censimento generale dell'agricoltura 2010. Available from: http://www.istat.it/it/censimento-agricoltura

ISTAT, 2011. $15^{\circ}$ Censimento della popolazione e delle abitazioni 2011. Available from: http:/www.istat.it/it/censimento-popolazione/popolazione-2011

Jankowski P, 1995. Integrating geographical information systems and multiple criteria decision making methods. Int. J. Geogr. Inform. Syst. 9:251-73.

Janssen R, Rietveld P, 1990. Multicriteria analysis and geographical information systems: an application to agricultural land use in the Netherlands. In: H.J. Scholten, J.C.H. Stillwell (eds.) Geographical information systems for urban and regional planning. Kluwer Academic Publishers, Dordrecht, the Netherlands, pp 129-39.

Jiang H, Eastman JR, 2000. Application of fuzzy measures in multi-criteria evaluation in GIS. Int. J. Geogr. Inform. Syst. 14:173-84.

Makropoulos C, Butler D, 2005. Spatial ordered weighted averaging: incorporating spatially variable attitude towards risk in spatial multi-criteria decision-making. Environ. Model. Softw. 21: 69-84.

Makropoulos C, Butler D, Maksimovic C, 2003. A fuzzy logic spatial decision support system for urban water management. J. Water Resour. Plann. Manage. 129;69-77.

Malczewski J, 1996. A GIS-based approach to multiple criteria group decision making. Int. J. Geogr. Inform. Syst. 10:955-71.

Malczewski J, 1999. GIS and multicriteria decision analysis. John Wiley \& Sons Inc., New York, NY, USA.

Malczewski J, 2004. GIS-based land-use suitability analysis: a critical overview. Progr. Plann. 62:3-65.

Malczewski J, 2006. Ordered weighted averaging with fuzzy quantifiers: GIS-based multicriteria evaluation for land-use suitability analysis. Int. J. Appl. Earth Observ. Geoinf. 8:270-7.

Malczewski J, Chapman T, Flegel C, Walters D, Shrubsole D, Healy MA, 2003. GIS-multicriteria evaluation with ordered weighted averaging (OWA): case study of developing watershed management strategies. Environ. Plann. A 35:1769-84.
Mendes JFG, Motizuki WS, 2001. Urban quality of life evaluation scenarios: the case of São Carlos in Brazil. CTBUH Rev. 1:1-10.

Mercurio R, Minotta G, 2000. Arboricoltura da legno. CLUEB, Bologna, Italy, pp 111-78.

Minotta G, Facciotto G, Bergante S, Frenguelli L, Giovanardi R, Gras M, Maggiore T, Mughini G, Muzzi E, Bonari E, Seufert G, Zenone T, 2007. Ongoing researches on the productivity of SRF plantations in Italy. pp 15-18 in 15th Proc. Int. Conf. European Biomass Conference \& Exhibition, From research to market deployment, Berlin, Germany.

Ragaglini G, Villani R, Silvestri N, Bonari E, 2011. Il contributo delle colture dedicate al settore delle agroenergie in Toscana: sviluppo di un modello previsionale su base GIS. L'Italia Forestale e Montana. 66:267-81.

Rashed T, Weeks J, 2003. Assessing vulnerability to earthquake hazards through spatial multicriteria analysis of urban areas. Int. J. Geogr. Inform. Sci. 17:547-76.

Rasmussen BM, Melgaard B, Kristensen B, 2001. GIS for decision support-designation of potential wetlands. p 107 in 3rd Int. Conf. Geospatial Information in Agriculture and Forestry, Denver, CO, USA.

Rinner C, Malczewski J, 2002. Web-enabled spatial decision analysis using ordered weighted averaging. J. Geogr. Syst. 4:385-403.

Romano S, Cozzi M, 2008. Valutazione delle trasformazioni del suolo e delle dinamiche in atto mediante analisi territoriale e metriche statistiche: il caso dell'hinterland potentino, Basilicata. Agribusiness Paesaggio \& Ambiente 11:98-108.

Romano S, Cozzi M, 2006. Il governo del territorio e la conservazione delle risorse: l'uso dei modelli geografici multicriteriali per la valutazione del rischio socio economico e ambientale degli incendi boschivi. Riv. Econ. Agr. 3:365-400.

Saaty TL, 1980. The analytic hierarchy process. McGraw-Hill, New York, NY, USA.

Sacchelli S, De Meo I, Paletto A, 2013a. Bioenergy production and forest multifunctionality: a trade-off analysis using multiscale GIS model in a case study in Italy. Appl. Ener. 104:10-20.

Sacchelli S, Fagarazzi C, Bernetti I, 2013b. Economic evaluation of forest biomass production in central Italy: a scenario assessment based on spatial analysis tool. Biomass Bioener. 53:1-10.

Salvati R, Chirici G, Corona P, 2007. Modello di valutazione dell'attitudine fisica del territorio per la realizzazione di impianti cedui da biomassa in Italia. I.F.M. 5/6:399-410.

Tenerelli P, Carver S, 2012. Multi-criteria, multi-objective and uncertainty analysis for agro-energy spatial modelling. Appl. Geogr. 32: 724-36.

Thill JC, 1999. Multicriteria decision-making and analysis: a geographic information sciences approach. Ashgate, New York, NY, USA.

UNEP, 2011. Towards a green economy: pathways to sustainable development and poverty eradication. United Nations Environment Programme, Nairobi, Kenya. Available from: http://www.unep.org/ greeneconomy

World Bank 2012. Turn down the heat: why a $4^{\circ} \mathrm{c}$ warmer world must be avoided. World Bank Washington, DC, USA. Available from: https://openknowledge.worldbank.org/handle/10986/11860

Yager RR, 1988. On ordered weighted averaging aggregation operators in multi-criteria decision making. IEEE Trans. Syst. Man Cybernet. 18:183-90

Yager RR, 1996. Quantifier guided aggregation using OWA operators. Int. J. Intel. Syst. 11:49-73.

Zadeh LA, 1965. Fuzzy sets. Inform. Control. 8:338-53.

Zadeh LA, 1983. A computational approach to fuzzy quantifiers in natural languages. Comput. Math. Appl. 9:149-84. 